\title{
Teaching and Learning in Two iPad-Infused Classrooms: A Descriptive Case Study of a Dual Classroom, School-Based Pilot Project
}

\author{
Kimberly Maich \\ Memorial University \\ Carmen L. Hall \\ Fanshawe College of Applied Arts and Technology \\ Tricia Marie van Rhijn \\ University of Guelph \\ Megan Henning \\ Brock University
}

\begin{abstract}
This multi-methods, descriptive case study examines attitudes and practices of classroom-based iPad use. The site is one inner-city, urban, publicly funded school, focused on two iPad-infused classrooms (Grade 2/3 and Grade 4/5). Data were collected from 5 educators and 35 students to investigate two research questions: How are iPads being utilized in student instruction? How do educators and students perceive the value of using iPads in the classroom? For this study, we analyzed the transcript of a focus group with five educators, data from 10 days of structured student observations, and the results from 35 student questionnaires. Five themes emerged from the focus group; the strongest related to pedagogical practices. Data related to student perceptions indicated a positive attitude toward iPads. They enjoyed iPad use, were concerned about equity issues, had high self-ratings about related skills, felt they used it most often in Mathematics, and indicated various preferred applications. Overall, iPads were used in 31.7\% of observed instructional time, 94.7\% of which was facilitated by classroom teachers. Of this iPadbased instructional time, $72.5 \%$ was for individualized teaching, typically in language and/or mathematics instruction. Our analysis culminates in recommendations for school leadership such as teaching prerequisite skills and providing ongoing technological supports.
\end{abstract}


The introduction of user-friendly, portable digital technology such as tablet devices has changed education (Churchill \& Wang, 2014): "Twenty-first-century technologies are also about the portability of mobile digital devices which now have the potential to allow any-time access" (Male \& Burden, 2014, p. 424). Apple iPad's popularity has soared in schools, likely due to elements such available educational applications (apps), built-in accessibility features with user-friendliness for a diverse population, and strong levels of support (Draper Rodríguez, Strnadová, \& Cumming, 2014). Despite widespread adoption of iPads, there has been limited research to support their use in education; rather, many questions (e.g., What barriers arise?) are just beginning to be addressed.

\section{Vignette}

The combined Grade 2/3 class in an inclusive, inner-city schools buzzed with the active sounds of teaching and learning. In a "baptism by fire," the classroom had leapt with excitement and courage into using iPads along with everyday teaching and learning. During their language class, today, all students had iPads on their desks, and were engaged in creating graphic organizers using various apps, sharing ideas verbally, while tapping their on-screen keyboards, and sending finished projects to the class's shared electronic drop box or their wireless printer. Their teacher circulated among the students, demonstrating different features of the app on the integrated white board, as needed, while supporting students with their literacy goals. An educational assistant was also supporting the class, paying particular attention to individualized programs and the needs of varied grade levels present in the group (one student, for example, was listening to an e-book while watching the text highlighted on the screen as the electronic voice simulator read it aloud). Some students were struggling to engage in the writing component of their iPad-infused activity; others were already moving on to their subsequent rewards-a few minutes with a fast-paced, game-based math skills app. All students were engaged, but engaged differently, depending on their own needs, skills, and goals. Everyone was accomplishing something toward the ultimate goal: student achievement.

\section{Purpose}

Technology is a ubiquitous resource used over multiple settings that has the power to transform pedagogy (Leer \& Ivanov, 2013; Male \& Burden, 2014); however, technology appears to be adopted in school settings inconsistently, from a piecemeal manner for complex individual needs to its systematic implementation in a classroom, school, or school board. Complicating this inconsistency are additional issues, such as a potential disconnect between the intended purposes of technology purchased for educators and its actual use by educators, the practical inconveniences of its implementation (i.e., shared technology), or confusion when one technology is purchased for multiple, competing agendas (Chen, 2008). The adoption, use, and effects of technology may precede systemic research or proceed without attention to contextual goals and changes in attitudes, knowledge, and/or skills. At the time of this project, research investigating school-based teaching and learning around tablet technology was just emerging - and is still growing as a body of knowledge. We are truly just learning how iPads support classrooms, and many questions remain, some of which are addressed in this study: How 
are iPads being utilized in student instruction? How do educators and students perceive the value of using iPads in the classroom?

\section{Literature Review}

In acknowledging the increased adoption of iPads in educational settings, it is essential to examine the numerous ways such technology supports current classroom structures as well as its rapid integration into our classrooms.

\section{1st-Century Education}

Schleicher (2012) suggested that students require a refined skill set in order to be successful in fast-paced 21 st-century society. These skills include collaboration, communication, problem solving, and creativity (Luterbach \& Brown, 2011; Schleicher, 2012). Luterbach and Brown (2011) proposed that students function best when they are taught these skills and learn the interrelation of overlapping societal systems. In other words, students need to understand that skill sets are transferable between environments, and that our world is transforming into a digital platform where many of these skills are demonstrated through technologically based formats (Murray \& Olcese, 2011; Schleicher, 2012). The term code-switching has been used to describe these sets of transferable technological skills, where students unconsciously use a technological set of skills in other environments (Turner, 2009). Clearly, technology is firmly a part of 21 stcentury education (Leer \& Ivanov, 2013).

Integration of technology is important due to its potentially participatory nature, which supports an active inquiring, creating, critiquing, and problem-solving experience of knowledge acquisition (Male \& Burden, 2014). Furthermore, technology provides opportunities to expand beyond traditional classrooms into societal, global platforms (Leer \& Ivanov, 2013). Male and Burden (2014) explained that the integration of technology into 21 st-century education is necessary; that incorporating technology into educational practice allows students to learn in a manner consistent with their reality. Technologies such as laptops, SMART boards, and mobile phones support this; moreover, Murray and Olcese (2011) identified tablets as a popular and effective choice because of size, flexibility, and relatively low cost.

\section{Tablet Technology in Inclusive Classrooms}

The integration of tablets in education provides haptic, touch-based technology: a means to connect with the world in an engaging, flexible, and immediate way, right within classrooms (Crescenzi, Jewitt, \& Price, 2014; Flewitt, Kucirkova, \& Messer, 2014). Murray and Olcese (2011) commented that iPads have become one of the most popular classroom-based touch technologies. Research has demonstrated that iPads can increase student motivation, enthusiasm, and collaboration, allowing for sharing and immediate feedback, all of which are 21st-century essentials (Crescenzi et al., 2014; Falloon, 2015). Specifically within Falloon's (2015) study, nearly 100 students were consulted on their opinions regarding classroom iPad use through the use of focus groups and questionnaires. Students within Falloon's (2015) research shared many reasons why they enjoyed using 
the iPad, including the ease with which they could share their work, mobility, and learning support through applications and collaboration. Falloon (2013) wondered, though, if we are being "seduced" by such trendy, "fashionable" technological tools.

Creszenski et al. (2014) suggested that iPads support diversity, recognizing a variety of gestures, motions, and touches that utilize varied motor skills (Cumming \& Draper Rodriguez, 2013) and provide educators with a means to support students in varied programs (e.g., literacy support; Pellerin, 2013). In comparison to previous assistive technology tools, the now commonplace use of iPads has led to social acceptability and somewhat easier integration than previous technologies, while avoiding ability-based segregation (Cumming \& Draper Rodriguez, 2013; Flewitt et al., 2014). Flewitt et al. (2014) noted that this allows students with exceptionalities to be empowered and to connect socially, finding that students expressed their preference for iPads due to ease of use and engagement. iPads have accessibility features that allow built-in physical, behavioural, and learning accommodations for persons with disabilities without costly additional software, allowing students with exceptionalities to explore new communications, such as apps to communicate needs by drawing (Cumming \& Draper Rodriguez, 2013; Flewitt et al., 2014). Initial research has been completed with the iPad compared to other tablets, as Apple was the first company to introduce tablet devices (circa 2010); Apple continues to provide education and support to schools (Apple, 2014). Although there are components of research that can apply to all tablets, there are specific education-based apps and built-in accessibility features built for students with disabilities, for education, that cannot be necessarily generalized from the iPad to other tablet devices (Cumming \& Draper Rodriguez, 2013).

Despite developing evidence of the diverse benefits associated with classroom iPad use, concerns such as internet dependence, teacher training, and loss of tactile experiences have been suggested within recent studies as potential limitations (Crescenzi et al., 2014; Cumming \& Draper Rodriguez, 2013; Ward, Finley, Keil, \& Clay, 2013). As schools become more technologically inclined (Male \& Burden, 2013), teachers and students are provided with increased opportunities and training with technology devices such as the iPad, allowing a learning experience reflective of the reality of a digital 21 st century (Leer \& Ivanov, 2013).

Ultimately, the integration of tablet and other touch technologies in education provides all students with opportunities to engage in more interesting and technologically infused ways than ever before, with the potential to transform practice (Murray \& Olcese, 2011). Despite increasing educational use, however, there is still limited empirical evidence of student and teacher opinions, research evaluating how it is used, and efficacy to support such implementation (Cumming \& Draper Rodriguez, 2013; Leer \& Ivanov, 2013).

\section{Methodological Framework}

This study is a multi-method, single-site case study utilizing both qualitative and quantitative traditions focusing on descriptive research (Creswell, 2013; McMillan, 2012) while relying on observations to obtain a "picture of occurrences, situations, and contexts" (Mertler \& Charles, 2011, p. 111). Using this approach, we investigated two research questions within inclusive classroom settings in one inner-city school: (a) how 
are iPads being utilized in student instruction? (b) How do educators and students perceive the value of using iPads in the classroom?

\section{Methods}

The research was conducted in two publicly funded inner-city, inclusive classrooms (Grades 2/3 and 4/5) in an area with one of the highest percentages of low-income Canadian family situations within the Greater Toronto Area in Ontario, Canada (Toronto Child \& Family Report Card Working Group, 2016). For the purposes of this study, inclusive classroom refers to those in which children with disabilities are educated along with typically developing peers in neighbourhood schools. These classrooms were also iPad-infused classrooms, meaning each classroom had dedicated classroom sets of iPads - one for each student and educator. A case study methodology was selected to meet the needs of this research in order to fully develop and understand a specific case (Stake, 1995), utilizing student observations, student questionnaires, and a focus group of involved educators. Case studies provide an examination that is in-depth and focuses on people, programs, topics, or issues within a particular bounded system (Hays, 2004; Stake, 1995). Descriptive case studies are further used to fully examine and develop an understanding of a particular system (Stake, 1995; Yin, 2003). Case study inquiry is most successful when multiple forms of evidence are collected and analyzed, including both qualitative and quantitative evidence (Gillham, 2000; Yin 2003). While qualitative evidence and analysis are predominant, quantitative data is useful to add to the overall understanding of the case (Gillham, 2000). Triangulation of the qualitative and quantitative evidence can strengthen understanding (Yin, 2003). Furthermore, case study research should "not start out with a priori theoretical notions ... because until you get in there and get hold of your data, get to understand the context, you won't know what theories (explanations) work best or make the most sense" (Gillham, 2000, p. 3). These essential strategies were followed as described in the next section.

\section{Data Collection and Analysis}

Prior to the initiation of this research project and wholly independently from this project, two classrooms had been nominated by the school's principal to opt into in a school-board-wide initiative to purchase and distribute class sets of iPads to willing schools, classrooms, and educators. These classrooms had acted as "pilots" in this boardinitiated project, meaning that the first class used iPads for two years, and the second class for one year. In the first classroom, iPads moved with the students to the new teacher the following year.

When the current research project was initiated independently following this boardinitiated pilot project, all educators from both years one and two of this board-initiated pilot were subsequently invited to participate in a focus group. All students in both classrooms were also invited to participate in the observations and questionnaires described below. Data collection commenced following research ethics clearance, school board approval, parental consent, and student assent and lasted from March to May 2013.

Observations and questionnaires. Quantitative data were collected through in-class

observations and student questionnaires. In each classroom, a total of five full school 
days of structured in-class observations were undertaken in March and April 2013, utilizing a momentary time sampling data collection sheet divided into 10-minute observation intervals throughout the full school day (excluding nutrition breaks). After consulting with educators around observation days, we followed a variable schedule to "reflect more accurately normal [natural] classroom use patterns and range of use conditions" (Falloon, 2013, p. 507). It is important to note that the educators were consulted regarding appropriate observation days. In sum, for Grade 2/3 observations took place on one Wednesday, one Friday, and three Mondays; for Grade 4/5 observations took place on one Monday, one Wednesday, and three Fridays. On those days, data collection in each of the 10-minute observation intervals included visual observations by a research assistant taking manual recordings on a structured data collection sheet (i.e., any iPad usage, simultaneous technology usage, group composition, curricular links, and staff members involved, along with text-based recording of further descriptive details, as needed). Usage percentages for the full sample (i.e., combined Grade $2 / 3$ and Grade 4/5 observations) were calculated using the total observations $(N=$ 287); usage percentages for each classroom used the total number of observations in that room (Grade 2/3, $n=139$; Grade 4/5, $n=148$ ).

Data related to student perceptions of iPad use in the classroom environment were gathered using 35 student questionnaires (Table 1): 16 from Grade 2/3 and 19 from Grade $4 / 5$. The sample consisted of more boys $(62.9 \% ; n=22)$ than girls $(37.1 \% ; n=13)$. Overall, the student participants ranged in age from 7 to 11 with a mean age of $8.9(S D=0.94)$.

\section{Table 1}

\section{Student Questionnaire (Text Only)}

\begin{tabular}{ll}
\hline \multicolumn{1}{c}{ Question } & \multicolumn{1}{c}{ Response Type } \\
\hline What is your gender? & [Options] \\
What is your age? & [Options] \\
I have used the iPad in my classroom & Yes-No \\
I have used the iPad in these classes: Language, French, & Yes-No \\
Mathematics, Science \& Technology, Social Studies, Health \& & \\
Physical Education, Art & \\
What is your favourite class to use the iPad in? Why? & Open-ended \\
What is your favourite activity on the iPad? Why? & Open-ended \\
Is there anything you do not like about using the iPad? What is it? & Open-ended \\
Do you think you are good at using the iPad? & Sentence completion / \\
& structured choice \\
How does the iPad make you feel? & Sentence completion / \\
Should every student use an iPad at school? Why or why not? & Structured choice \\
\hline
\end{tabular}

The questionnaires consisted primarily of Likert-scale and checklist-based questions that were completed with the student and the researcher. The students were either able to complete these on their own or were scribed by the researcher, depending on the skill level 
of the child. All questions had the inclusion of visuals (i.e., happy, neutral, sad faces) to further enhance accessibility and understanding. Questionnaires took 4-11 minutes to complete, depending on the child. Open-ended questions were thematically analyzed by examining the repetition of like responses as well as unique contributions with seminal meanings. The use of student questionnaires helped this study move beyond Ditzler, Hong, and Strudler's (2016, p. 285) observed unidirectional influence of iPad use ("How the teachers used the device was indicative of how the students would use it") to Beauchamp, Burden, and Abbinett's (2015) suggestion that iPad teaching and learning is at least a bidirectional undertaking: "We also need to look at what pupils say, as they are very influential in developing teachers' use of the iPad" (p. 167).

Table 2

\section{Focus Group Questions}

\begin{tabular}{|c|c|}
\hline Category & Question \\
\hline Demographics & $\begin{array}{l}\text {-What is your role in the classroom? } \\
\text { - What is your role using iPads in the classroom? }\end{array}$ \\
\hline Attitudes & $\begin{array}{l}\text { - On a scale of } 1-5 \text { with } 5 \text { being the MOST comfortable and } 1 \text { being the } \\
\text { LEAST comfortable, how comfortable do you currently feel about using } \\
\text { educational technology to support your teaching practice? Why did you } \\
\text { choose this rating? } \\
\text { - How comfortable do you currently feel about using iPads to support your } \\
\text { teaching practice? Why did you choose this rating? }\end{array}$ \\
\hline Practice & $\begin{array}{l}\text { - How often would you say you use iPads? } \\
\text { - For what curricular area would you say you typically use iPads? } \\
\text { - Do you typically use iPads for individual instruction, small group instruction, } \\
\text { - or whole class instruction? } \\
\text { - Do you collaborate with other educators when using iPads for instructional } \\
\text { purposes? } \\
\text { - Do you use iPads with students during non-instructional time? } \\
\text { - Do you use iPads for your own professional preparation/organization? } \\
\text { - Do you pair the use of the iPads with any other technology in the classroom? } \\
\text { individual students with or without exceptionalities? }\end{array}$ \\
\hline Benefits & $\begin{array}{l}\text { - Explain what student-related benefits exist when using iPads in the } \\
\text { instructional environment. } \\
\text { - Explain what teacher-related benefits exist when using iPads in a } \\
\text { professional environment. }\end{array}$ \\
\hline Barriers & $\begin{array}{l}\text { - Explain what student-related barriers exist when using iPads in the } \\
\text { instructional environment. } \\
\text { - Explain what classroom management barriers exist when using iPads in a } \\
\text { professional environment. } \\
\text { - Explain what teacher-related barriers exist when using iPads in a } \\
\text { professional environment. } \\
\text { - Explain what school-wide barriers exist when using iPads. }\end{array}$ \\
\hline Wrap-up & $\begin{array}{l}\text { - Is there anything else that you would like to add to this discussion that has } \\
\text { been missed? }\end{array}$ \\
\hline
\end{tabular}


Focus group. The experiences of involved school staff members were explored and interpreted in an emergent manner as the qualitative component of this study (Glense, 1999). These were collected through a focus group composed of five educators (two classroom teachers and two educational assistants currently using iPads, and one classroom teacher who previously utilized them). These principal-nominated educatorsall current and past educators in the school's iPad-infused classrooms-were invited to participate, and chosen to examine, "What is typical?" (Creswell, 2012, p. 208). This focus group took place in the school (May 2013), lasted 52 minutes, and was facilitated by the second author. It followed a whole-group semi-structured, open-ended interview script (Table 2, above), and was audiotaped using two digital recorders, then professionally transcribed. The resulting 24-page transcript was transferred to Dedoose software (SocioCultural Research Consultants, 2013) for analysis, organized into 21 in vivo codes from 113 excerpts of text, then further structured into five emergent themes.

\section{Results}

To formulate conclusions regarding iPad usage in these classrooms, observational, focus group, and questionnaire data were utilized. Results pertaining to the utilization of the iPads for the purposes of student instruction are followed by educator and student perceptions of the value of using iPads.

\section{Pedagogical Practices: iPad Utilization}

Overall, iPads were used during $31.7 \%(n=91)$ of the total observations during the 10 classroom observation days $(N=287)$. During these observations, classroom teachers were the primary adult facilitators of such usage $(94.7 \%)$ followed by educational assistants $(5.3 \%)$, likely reflective of typical pedagogical leadership patterns of classroom teachers. Additional technologies (e.g., SMART boards, projectors) were utilized in $17.1 \%$ of observations, and concurrently with iPads $32.7 \%$ of the time.

iPads were in use during $30.9 \%$ of the Grade $2 / 3$ observations and $32.7 \%$ of the Grade $4 / 5$ observations. A Pearson chi-square test failed to indicate any significant difference between the classes, $\chi^{2}(1)=.07, p=.79$; however, a significant difference existed in weekly patterns of use, $\chi^{2}(2)=34.1, p<.001$. For the Grade $2 / 3$ class, iPads were primarily in use on the three observed Mondays ( $81.4 \%$ of the time), $18.6 \%$ of the time on the one observed Friday, and not in use during the Wednesday observation. For the Grade 4/5 class, iPads were primarily in use on the three observed Fridays $(66.7 \%)$, $20.8 \%$ of the time on the one observed Monday, and $12.5 \%$ on the one observed Wednesday. (It is important to note that results for higher Monday usage for the Grade $2 / 3$ class and Friday usage for the Grade 4/5 class relates directly to the increased observational time that occurred on these days; 3 Mondays for the Grade 2/3 class and 3 Fridays for the Grade 4/5 class compared to only one day each for the other days.) No significant differences were found between the two classrooms based on time of the day, $\chi^{2}(1)=1.4, p=.27$, but morning usage was more common $(72.1 \%$ of the Grade $2 / 3$ observations; $60.4 \%$ of the Grade $4 / 5$ observations), perhaps reflective of preferred patterns of instruction with core curriculum areas scheduled in morning classes. Further comparing these two classes using the Pearson chi-square, there were significant 
differences based on group composition, $\chi^{2}(2)=7.0, p=.03$. Most commonly, iPads were in used during individual instruction ( $72.5 \%$ of total observations), followed by $20.9 \%$ during whole group instruction, and $6.6 \%$ during small group instruction. For the Grade $2 / 3$ class, the iPads were more frequently observed during individual instruction $(81.4 \%)$, compared to either small or whole group (each at 9.3\%). For the Grade 4/5 class, individual instruction was also the most frequent $(64.6 \%)$, but there was more use during whole group instruction (31.3\%) than during small groups (4.2\%).

iPads were not observed being utilized by students as directed by the classroom teacher during science and technology, French as a second language, or health and physical education for either grade across all observation periods. During our observation of these subjects, educators directed student learning in other manners (i.e., worksheet, group activity, etc.) while the iPads were on the charging cart. When rates of usage from the two classes were examined together, the most common curriculum area observed was writing $(25.6 \%)^{1}$. Other curricular areas encountered during observations included mathematics $(22.2 \%)$, social studies $(18.9 \%)$, religion $(13.3 \%)$, art $(8.9 \%)$, language $(6.7 \%)$, reading $(2.2 \%)$, and non-instructional time (e.g., announcements, breaks; $2.2 \%)$. Figure 1 provides the observations broken out for each class. The most common curriculum area in Grade 2/3 was mathematics, and language in Grade 4/5-also typical areas of instruction focus in elementary classrooms. Usage during non-instructional time without formal curriculum was only observed in Grade $2 / 3$, and usage during art instruction occurred only for Grade 4/5. Qualitative examples of these pedagogical practices follow.

Figure 1. Percentage of Observed iPad Use by Curricular Area and Classroom

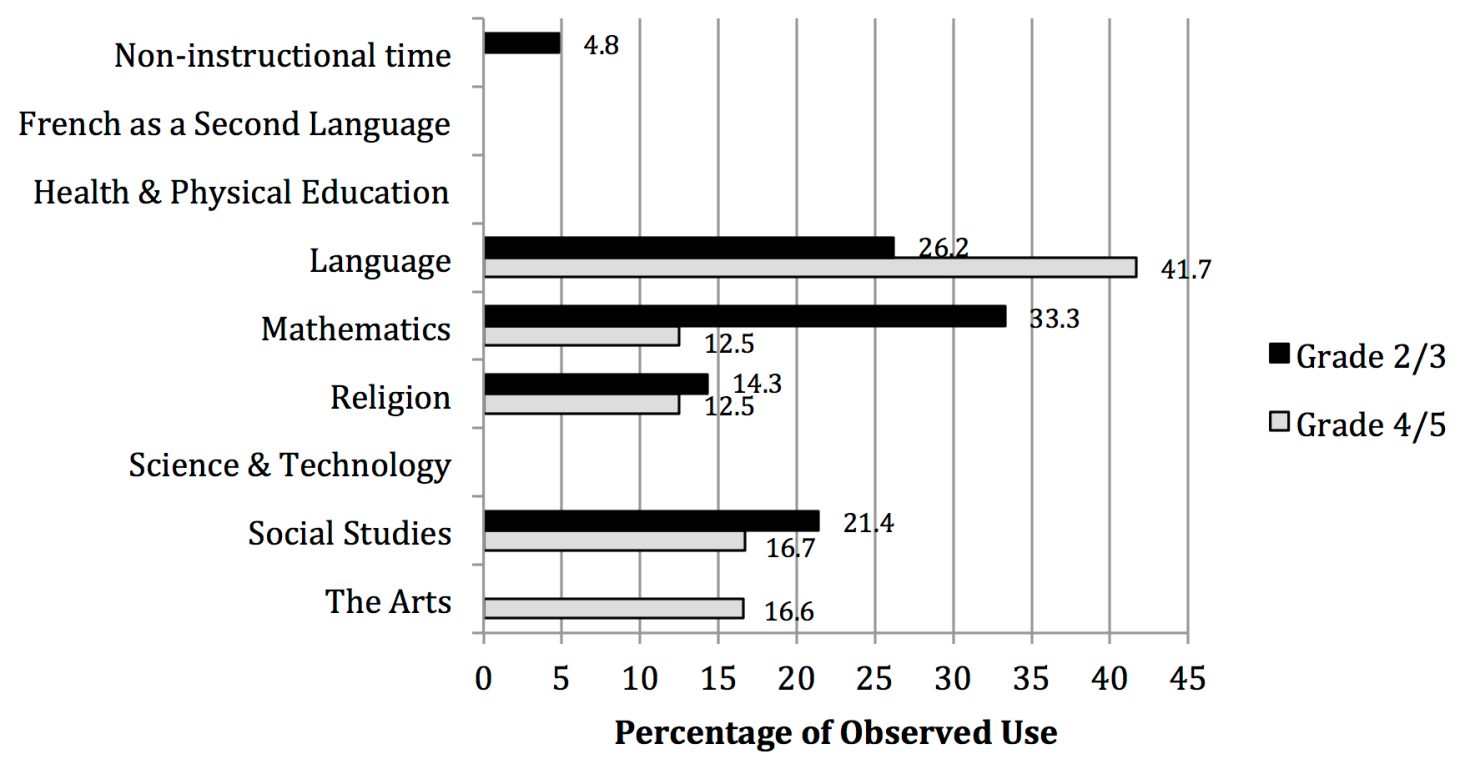

\footnotetext{
${ }^{1}$ In Ontario schools, writing and reading are strands of Language (Ontario Ministry of Education, 2006).
} 


\section{Perceptions of iPad Use in the Classroom}

Using a process of emergent thematic analysis for focus group data, we first identified 21 codes, which were then incorporated into five main themes related to the educators who participated in this pilot study.

Theme 1: Clearly comfortable. The first theme is comfort with technology in the classroom, including iPads. During focus group discussions, the five focus group participants rated comfort (on a scale of 1-5) at an average of 4.2 for classroom iPads (range: 2-5), and 4.6 for technology in general (range: 3.5-5). These participants are quite comfortable with both technology in general and iPads, specifically. Only one outlier selected a low self-rating (2.0): "I'm not very comfortable with technology. I don't understand it that much" (Grade 2/3 educational assistant). Two participants differentiated between the ease of using known technology with automaticity, and the challenge of using novel technology with significant learning curves. In other words, it is not difficult to imagine that a focus group carried out at the initiation of the iPad pilotwhen iPads would have been a novel technology for these educators - may have provided a different message.

Theme 2: Pedagogical practices. Overall, participants indicated that iPads were utilized regularly, for "a good chunk of the day" (Grade 2/3 teacher), supporting the observational data. Their use was noted primarily in language (e.g., writing), and mathematics (e.g., fluency), also consistent with observational data. This second, and strongest, emergent theme relates back to the provision of a range of intentional pedagogical practices related to iPad use: from deliberate strategies around disability and differentiation (i.e., iPads for all students), to the provision of subject-specific linkages to iPads (e.g., using iPads for writing), to deliberate support for skills development within curricular areas (e.g., fine motor skills), to a strong focus on teaching and learning the specific apps themselves (e.g., Write 2 app). All of the pedagogical practices were noted by the focus group educators as examples of their intentional, structured infusion of iPads into the pedagogical practices of their classrooms.

While educators were planning specific teaching and learning experiences with iPads, students were also taking control of their own learning and being independent, as part of the theoretical underpinnings of 21st-century learning by using the iPad. Yet, it wasn't all easy; educators commented that, first, building foundational processes and boundaries around iPads was time-consuming and essential before independence could happen:

You're focusing on the curriculum and the task that you have with that, but you have to teach the whole process of the app. So, for example using the Write 2 app, we had to now teach that, and then have them write their story or whatever it is: their actual task. (Grade $4 / 5$ teacher)

It is evident that there are layers to creating effective pedagogy to using the iPads with success, ranging from teacher training and practice with the iPads and its apps, to student training with the iPads and its apps, and only then to the independent operation of iPads to meet academic goals.

Language instruction dominated discussions around pedagogy, which also aligns with observational data: “We're using them every day ... I can't say we're using them all 
day long, but definitely for at least ... one to two periods in literacy" (Grade 2/3 teacher). For example: "Children wrote stories, drew the graphics, wrote the music, or found the music, did the work, really creative, funny, really good stuff" (Grade 4/5 educational assistant), and "The whole writing process you could do on the iPad. You could do the brainstorming, you could do the rough work, you could use $N+$ otes even, and then have it emailed" (former Grade 3 teacher). The focus group educators were clearly impressed with the breadth of the curriculum-related possibilities that the iPads offered, as well as with the possibilities in teaching discrete skills in an innovative manner. Again, though, challenges were present:

[They] could use any app that was a consolidation or as a reinforcement very quickly and very easily because it was something quick and fast for them. But when it came down to using it in a manner that they had to write out or do a journal on, it became painstaking. And it was, "Oh, but I don't want to use this app; I want to use this app." We always started off with $N+$ otes, we used $N+$ otes for a long time then we went to Write 2 to use as our app, and now that's the one that we use, because it's more like a word processor. (Grade 2/3 teacher)

It seems that utilizing the iPad has created another layer of decision-making: what application to use. While choice is generally considered to be a positive, the time and cognitive energy devoted to decision making must be acknowledged. Nevertheless, inherently positive outcomes also emerged beyond planned instruction, such as creativity:

We're working on autobiographies. And normally, they would write their information, get some pictures, put it on a Bristol board. So they're doing it all on their iPad and they're taking photos from home and they're taking photos of their photos, so they have them in their iPads and now they're attaching them to whatever program. I've given them options: some of them are using Animoto; some are going with a timeline app. So you can be quite creative; their creativity comes through in various ways. (Grade $4 / 5$ teacher)

While working on the planned curricular outcomes and activities (e.g., autobiographies) students were also taught and learned micro-skills in iPad management (e.g., picture taking), the use of new apps. As well, unexpected outcomes like the expression of creativity, were evident.

Mathematics tended to be a secondary pedagogical area for these educators utilizing iPads for everyday teaching and learning; an area where their experience and comfort levels grew over time. For example:

We did "drill and kill" from September until June on it where they had to chart it and pick goals. Some worked their way from two-digit addition up to multiplication, and others stayed; they were all sort of on their own page and doing their own thing, and that was like 10 minutes a day that we did it. And then we went to a couple [of] workshops so we used that, the math program: Numbers. We used that to do some graphing. I was much more comfortable with literacy than I was with math, but towards the end [students] were using it. (former Grade 3 teacher)

Creative outcomes noted in Language were also reinforced in Mathematics:

We were making skeletons of 3D shapes. They took pictures of each of their skeletons and then wrote paragraphs on them, handed them in, so they used a variety 
of different things, attached the pictures, sent them off. So it's very creative on their part and they'll say "Miss, just take a picture of it." Everything's "just take a picture of it" now. (Grade 2/3 teacher)

Though educators are seeing similar patterns of engagement and outcomes in Math, their own comfort levels needed more time for growth and development in comparison to literacy-based apps. Much like the educators in this study, Courduff, Szapkiw, and Wendt (2016) found that individual attitudes and beliefs (potential second-order barriers; see D'Agostino, Rodgers, Harmey, \& Brownfield, 2016) — but also opportunities - paved the way for special educators to "begin exploring and adopting technology in small steps" (p. 35 ) in ways that were both planned and spontaneous, over time.

Theme 3: Barriers and benefits. The third theme encompasses how educator participants perceived both benefits and barriers in using iPads for everyday instruction. Interestingly, there was an equal balance between benefits and barriers.

Benefits. Benefits included the autonomous use of one-to-one devices, the customization and reciprocal interaction, tailoring for individualized learning, and sustainable classroom practices. The autonomous use of individual devices in the classroom provided individuals with the ability to have independence while learning and have easily accessible information, thus allowing for the efficient use of class time for each student to interact with and manipulate the information. The learning was also customized, in that it provided choice for the student, allowed them to communicate in multiple manners and methods, and allowed them to interact with the material rather than just receive the information. Additionally, the iPads allowed for individualized instruction and learning whereby the students expressed enjoyment, demonstrated engagement and creativity, were reinforced in their learning, and built self-esteem based on their individual success. Lastly, the iPads allowed for changes in sustainable classroom practices including increased efficiency of class time, organization, planning, and eco-friendliness with less reliance on paper. "It was never," one educator emphasized as dubious pedagogy, "go find your own free app and play with it" (Grade 2/3 teacher).

Alternatively, iPads supported classroom management through curricular engagement around consolidation of skills. Even though the following comment overestimated iPad usage according to observational data, the feeling of immersion in this technology is evident: "We used them all day, every day: by January, it was on their desk from morning to lunch, and then from after lunch till end of the day. There was no down time. They always had something to work on" (former Grade 3 teacher). As well, they acted as a pedagogically based positive reinforcer: "Everyone has access to it at the same time, so it's kind of neat" (Grade 4/5 teacher). Educators reflected that iPads saved time and energy beyond even the use of laptops, even though this enthusiasm about increased efficiency contradicts some comments from other educators noted above (see Theme 2: Pedagogical practices).

It's a lot easier just to say "Pull out your iPads" than before. I took the kids to the computer lab, [and] they would say "I don't know my login" or "This isn't working" or "I can't see the ..." [but now] it's all saved on the iPad, you can't lose it, it's impossible. (Grade 2/3 teacher) 
Beyond this benefit of time compared to previous whole-class technology use, iPads also worked as accessible aids in discovering curriculum-related content with greater independence, efficiency, and effectiveness, such as in this language example: "It's a great hands-on tool for research, too, just to have to have it at your fingertips. Like this week we're working on autobiographies, and they just did it automatically: They just went and Googled what their names meant." (Grade 4/5 teacher). As well, students enjoy the accessibility of visual examples not only to find and document ideas. A further noted benefit was, "They see the iPad as a reward. I've never used it as, 'Okay, get that done, then you can go on your iPad.' It's always been using it as reinforcement after Mad Math, that sort of thing" (Grade 2/3 teacher). In addition, one educator commented:

I only gave them choice of apps that coincided directly with my lessons, [then] if they're doing extra-if they're "behaving"-I'll say, "You know what? You've earned 15 minutes of free iPad time." And then give them a little certificate. (Grade $2 / 3$ teacher)

Although it is doubtful that every student sees the iPad as a reward, it is doubly rewarding when a learning tool and its applications themselves can be a reinforcer for curriculum engagement. For students who struggle with academics and need accommodations, or for students with exceptionalities, even more benefits were noted. Reflecting on supports for a student with special needs requiring an intensive level of classroom support, one classroom educator responded that some independence during individualized curricular-based learning was a novel outcome:

I can set him up on an iPad. The fine motor skills use helps. He can listen to books if he wants to read, [and] he could do the puzzles. It's a really good tool if you have to leave a child when he otherwise would do nothing by himself. He's actually engaged and I'm sure he's learning a lot of things. The apps that he goes on rewards them with something that at his level (clapping or balloons flying). It's a joy. So he knows he has done well. (Grade 2/3 educational assistant)

Finally, even the involved educators themselves saw benefits for their professional roles, such as planning, organization, and communication: "It was all right there. I took it home and I had the Dropbox app, so anything that they emailed I uploaded on Dropbox and no matter where I went ... I would just pull it up" (former Grade 3 teacher). Another recounted how it assisted with parent communication during on-site parent-teacher interviews:

It's so easy to show ... "Oh look, this is what they did" or "Here's their..." Normally I'd have all their books out, where's this and where's this, but they literally left their iPad on their desk, and when the parents walked in you picked it up and said "This is what they've done." (former Grade 3 teacher)

Barriers. Barriers to iPad use were a focus for some educators. One noted barrier was the varied skill levels inherent in their diverse, inclusive classrooms. Writing-with or without the $\mathrm{iPad}$ - was already an area in which students struggled, but the additional layer of learning related apps for writing created some additional barriers to writing efficiently:

[Writing with the iPad] became painstaking for some [students] and it was almost easier for some of them to go on to paper and pencil back again. It became a longer process to do it than I think sometimes with paper and pencil. (Grade 2/3 teacher) 
As in the above example, prerequisite skills for using the iPad affected its usability, at times, as a curricular tool. For example, one student struggled with persistent buttonclicking: "She doesn't press it once; it's like she keeps on: press press press press" (Grade 4/5 educational assistant). Educators also noted they had to be careful about setting boundaries and transitioning students from perceiving it as a toy for games. One participant described that "it's hard when, at home, it's a fun toy" (Grade 2/3 teacher), and another added:

It's a lot about setting boundaries and rules ... you have to really stress that it's a teaching tool because they're used to seeing it as a toy or a pastime and that's great, and a lot of those apps are both educational and can be fun. (Grade $4 / 5$ teacher)

Some while some educators noted the use of apps as positive outcome from using iPads, others had noted the teaching of apps as another layer of time and energy used in the process. Various other logistical concerns affected the successful use of iPads as a whole-class tool, such as waiting for a full class set to be available. Various concerns focused on technical issues, such as teaching educators how to manage and utilize the iPads as class-wide teaching and learning tools, and pervasive issues like uneven levels of technical support, hardware issues (e.g., battery longevity), and funding (e.g., for headphones or microphones, external keyboards, apps).

Finally, moving past the anxiety associated with such a change in teaching practice was important. One participant explained her own "Aha!" moment:

I would just say ... not to be afraid of it because it is so user-friendly. I remember last year I was so overwhelmed. But the first thing that we did with the Apple guy was he took us on to Maps, and we typed in the Colosseum, and he showed how you went right in it, and walked around. And I went back to my class and went, "My God." So we went into the Colosseum, we went into the CN Tower, and they did a compare and contrast. Something so simple and I was like, "Okay ... I can do this." (former Grade 3 teacher)

It seems that, as with any type of novel learning including new technology, attitude and skills go hand-in-hand reaching forward to success.

Theme 4: Community, connections, and change. The fourth theme includes the community, connections, and changes noted by the focus group participants; primarily, between the iPads and other technology, as well as connections to other professionals. In terms of other technology, participants identified internet-integrated apps that allowed for collaboration, such as iCloud, as a "great tool as far as having information at your fingertips" (Grade 4/5 teacher) and:

A kid would post a reading response and they'd have to comment on it. So they would comment on it and then I'd say to them, "Your homework tonight is to look at and comment on five." I could see who was on and who wasn't on [the app]. (former Grade 3 teacher)

Teachers enjoyed being able to monitor online engagement, but this brought another layer of connectedness to the educators after instructional hours - a caveat in this process. Connections to others within this school-based initiative and beyond were important to 
find out the what and how of apps: "How many nights I was on the phone going, 'Just try this,' or 'Try this"” (former Grade 3 teacher)? Another participant shared:

I went online because there's the whole group -it's amazing what you find-we've collaborated [on] sharing of apps. And really that's the best way to do it, is to be handson, even going out for coffee with a group of people that have an iPad and saying, "Hey, check out this app." Honestly, that's been the best learning. (Grade 4/5 teacher)

In the context of a school-based pilot project, it makes sense that participants did not yet have strong, local models for iPad use. Instead, they discovered an accessible, online community of practice. This type of support was important especially given that additional, formal support was only provided during the initial implementation:

I had a lot of support because it was a pilot ... the guys from Apple were in every month, who taught me the apps, who taught the kids the apps [but] this year, we were fighting ... because we wanted to keep them and we wanted to see if we could get more money. So we pushed and pushed ... now this year, [we] don't have that support because we're not on their "list." (former Grade 3 teacher)

Clearly, finding and creating an ongoing community of support was essential in this time of change.

Theme 5: Looking back and moving ahead. The fifth, and final, theme represents the focus group participants looking back on the inclusion of iPads, as well as looking ahead to next steps in iPad use. One educator described the beginning stages: "We were kind of unfamiliar with what was happening. Basically baptism by fire: You kind of learn what's happening and you just jump in" (Grade 2/3 teacher). The educator also noted that their students' reactions changed over time: "They're so excited initially, right? I think once the novelty of an iPad wears off (because it does eventually), I think they become more self-sufficient and they realize, 'I can do more than just play'" (Grade 4/5 teacher). Despite these initial adjustments, they encouraged other future iPad educators not to be afraid, noting that user-friendliness, simplicity, and supports make iPads eminently "doable." They also looked back to workshops that had enhanced their comfort levels in facilitating iPad use, such as learning to add the use of microphones and wireless printers to their cadre of iPad-linked technology. They looked forward to more technology integration such as future connections with large-screen SMART boards.

Student perceptions of value. Overall, students in this study supported the use of iPads in their classrooms. When asked about dislikes, most identified none (71.4\%), but some indicated technical challenges (e.g., apps crashing, losing work), a dislike of Mathematics apps because it was their worst subject, or apps that required significant amounts of typing. When asked about their abilities, all children reported skills, self-rating as good (44.1\%), really good (26.5\%), or expert (29.4\%). The majority reported using iPads makes them feel happy (91.2\%); two identified feelings of "normal" and "nervous."

When students were asked whether every student should use school iPads, the majority responded positively (67.6\%). Overall, they felt that iPads enhanced learning: helping them to learn more, get smarter, work harder, and providing better explanations. Several felt they helped them to learn to use technology, electronics, and the internet. Others noted that iPad use reduced environmental impact by saving trees (i.e., less paper 
use), and supported inclusivity: "If you can't read, the iPad can read for you." Among negative reactions, equity issues were the most frequent, including fairness, not having enough iPads, or that "little kids" might struggle: "If they get [an] iPad, they throw it on the ground, which could break it." Others had practical concerns including theft, wasting money, and using electricity.

All students reported iPads use during mathematics; in other areas, 88.7\% reported iPad use during social studies, $77.1 \%$ during language, $60.0 \%$ during art, $68.6 \%$ during science and technology, 8.6\% during French as a second language, and 5.7\% during health and physical education. These latter three contradict observational data; however, instruction possibly occurs less frequently in these curriculum areas and may have occurred outside the study's observation schedule.

When asked about their favourite class to use iPads, students most commonly supported their use during mathematics $(6 / 16 ; 37.5 \%)$, then art $(4 / 16 ; 25.0 \%)$, language $(3 / 16 ; 18.8 \%)$, and social studies $(2 / 16 ; 12.5 \%)$; one student responded that they didn't know. The students commented that math games were "fun," that the iPad helped them to "learn multiplication and division better." Art was favoured because of being able to draw, write, and colour pictures. Students who favoured using the iPad during language instruction (including reading and literacy) commented that "if you don't know a word, it tell [sic] you." Finally, using the iPad during social studies allowed the students to "learn about all sorts of stuff." Students noted that iPads, the variety of apps, and their challenge, made mathematics instruction fun and easier. In language, children reported enjoyment in reading on the iPad and looking up unfamiliar words. Using the iPad during social studies was identified as a favourite; it was fun and provided opportunities to learn more about the world. Art was identified as a preference due to iPad-based opportunities to draw and colour.

Specific favourite activities were also noted. When grouped by app type, beyond games-based apps, activities in mathematics, social studies, and art were most frequently identified. Mathematics apps included Math Bingo, Mad Math, Space Mathematics, Quick Maths, and the often-mentioned Place Value. Social Studies applications included My Town 2 and Pioneer Lands. Art apps included 123d Sculpt and Blackboard.

\section{Discussion}

Leer and Ivanov (2013) suggest that it is not the presence of technology that supports success, rather how it is utilized. Accordingly, the dual purpose of this study was to instrumentally describe the everyday use of iPads in classrooms, and explore perceptions of their use. In general, this study demonstrates that students and educators alike are firmly convinced of the iPad's utility, and derive enjoyment from their use as a pedagogical resource. Such attitudes are foundationally important for success, as noted in complementary research: "Underlying dispositions and beliefs were foundational to the application of skill and knowledge to instructional practice" (Courduff et al., 2016, p. 36).

Observational data demonstrated that iPads were in use approximately one-third of the time; unsurprising considering that rates of classroom integration for even funded technology can be low ( $<35 \%$; Anthony, 2012). Usage was most common with classroom 
teachers present, in the mornings, and during individual instruction. These findings were similar for the Grade 2/3 and 4/5 classrooms; however, there was more usage during whole group instruction for Grade $4 / 5$. In terms of subject areas, iPads were utilized more in writing and mathematics, with higher usage also in social studies, religion, and art. It is important to note higher usage for language periods in Grade 4/5, potentially a result of greater language requirements, whereas Grade 2/3 utilized the iPad more for mathematics. Using the keyboard proved to be more difficult for younger students, and thus completing work in pencil and paper may have been preferred for some language periods. In contrast, learning math facts in Grade $2 / 3$ was also important, and thus customizing math practice on apps was reported as a desirable use of the technology by these educators.

The educators had fairly strong levels of technological literacy, an important factor in utilizing technology (Anthony, 2012). Despite their comfort level, educators recognized the time commitment and challenges related to using iPads, as well as providing boundaries for their use. Wright (2015) posited that continuance theory supports why technology adopters persist, even if technology is not "easy" or even rife with impediments. Like the educators in this pilot, Wright stated:

Learning benefits have to outweigh the additional preparation effort before teachers were prepared to continue using these tools. Consistently, the message from the preservice teachers was clear: if they saw that learners were more motivated, learned more easily, concentrated more, collaborated more, and completed tasks to a higher standard than before, then they considered it was worth doing. (p. 467)

Educators did experience some difficulties implementing and using iPads. Considering that school-based technology use is intricate, challenging, and often experimental, it leaves implementation "hing[ing] on teachers' pedagogical insights and willingness to experiment" (Li \& Choi, 2013, p. 2). However, another study of special educators found that "despite the lack of structured training and professional development opportunities and, often, the lack of outside support, teachers selected and integrated technology using an intentional, fearless, and often serendipitous approach" (Courduff et al., 2016, p. 31). Educators in this study also noted positive outcomes (e.g., increased creativity); in many ways, they took on the role of "curators" of education through independent learning (Male \& Burden, 2014).

These educators perceived many benefits to using iPads in their classrooms, seeing them as flexible tools that facilitated learning. Likewise, Falloon (2015) found a range of technical aspects (e.g., low weight, small size, portability) that supported peer-to-peer collaborative learning. Educators also perceived barriers to their use, or what can be described as natural, unavoidable challenges (Laferrière, Hamel, \& Searson, 2013). Supporting differentiated instruction, for example, can be problematic with laptop-based instruction, when it is strongly teacher directed, but it can engage even unwilling students (Beckman, Bennett, \& Lockyer, 2014). In addition, educators noted the need to set usage boundaries and rules; in other words, the need to teach students behavioural regulation around iPads was essential (Webb, 2011). This speaks to the literature around 21stcentury learning and code-switching whereby students need to be taught the "language" of the technology-skills that are transferable across technology and become 
unconsciously used when learning the content (Turner, 2009). To be successful in the 21 st-century educational system, these technological skills, boundaries, and limits need to be taught (Luterbach \& Brown, 2011; Schleicher, 2012). Finally, educators identified an important institutional use factor: the need for technical support and training to help them manage iPads effectively (Anthony, 2012).

Connections to other professionals, an element of third-generation activity theory, provided important learning opportunities for educators, which can positively influence technology use (Anthony, 2012). The participants in this study, similarly, found a community of practice (albeit an online one). In turn, they will likely be future "showcasing" educators by encouraging novelty in their school community with their own expertise and on-site social capital (Li \& Choi, 2013), moving from a "horizontal" mode of transferring knowledge to a given context, to a "vertical" mode, developing collective, on-site knowledge (Webb, 2011). In this manner, technological "experts" emerge in the school and help others. This was the case in the current study: The previous year's teacher was able to pass on knowledge and coach the new teacher. Champions in technology and in integration of technology with pedagogy emerge and lead. This is a particularly important element, as Li and Choi (2013) found that:

Social capital within a school seems to play a predominant role in facilitating change in pedagogical use of technology, as well as enhancing teachers' receptivity towards the use of technology in teaching and learning, and their engagement in professional development. (p. 13)

Third-generation activity theory also suggests that school-based technology is developed through interactions with at least two interconnected systems - higher-level planning at a systems level (e.g., school district) and the immediate classroom context-whose processes can either impede or support success (Anthony, 2012).

These educators demonstrated that they wanted to continue to learn, fitting with the supposition in activity theory that such social development "unfolds over time" (Anthony, 2012, p. 339). Losing the initial, formal support provided during implementation, and lacking ongoing support are problematic. Without continued support, the success of future pedagogical practice with iPads may be hindered. It appears that what was intended as a supplement to teaching and learning instead complicated it: "It is the surfacing of these very contradictions that potentially limit teachers' classroombased technology use" (Anthony, 2013, p. 337). Although many classrooms have access to technology, schools often fail to use it consistently or to its full potential (Leer \& Ivanov, 2013); therefore, it is essential to further explore school-based use. Use of educational technology such as classroom iPads can be described as "patchy," "idiosyncratic," or "uneven" (Wright, 2015) when such initiatives depend on the procurement of piecemeal funding and support. Ongoing technological and pedagogical supports are required to ensure continuing classroom practice and success.

Students are an important element in the complex pedagogical practices building learning opportunities (Webb, 2011). Since "responsibility for learning rests with both the teacher and the learner" (Webb, 2011, p. 5), the responses of students must be taken into account (Leer \& Ivanov, 2013), and a strength of this study was the inclusion of student voices. All students believed that they had the skills required for iPad use, and 
most reported feeling positive. Interestingly, a few students also reported feeling normal or nervous. The former could relate to the peer-appropriate nature of the iPad itself, where is it is a typically utilized technology tool for everyday entertainment, minimizing how resources are perceived as binary-based, either for "regular" students or for "disabled" ones (Wendell, 1996).

Overwhelmingly, students felt that iPads enhanced their learning, but some expressed concerns (e.g., fairness, costs). Some of these concerns align with factors, such as cost, that Male and Burden (2014) have described as resulting in an "access denied" situation to the use of technology. These researchers refer to the issue of funding for technology as the "elephant in the room" (p. 432), but others refer to cost as a factor that will diminish over time (Leer \& Ivanov, 2013). Similar to Beckman et al.'s (2014) findings that classroom laptops were used most commonly for writing, these students used their iPads most frequently during writing activities.

\section{Limitations}

As this is a descriptive case study, its results are firmly grounded in the research context. These results are not intended to be generalizable to all classroom-based iPad pedagogy, or all classroom situations. The origin of some differing patterns of usage are unclear. One explanation for different levels of iPad integration in language, for example, could be related to a higher level of independent language tasks (and iPad use) for more advanced, junior-aged students, and more support and teaching necessary for primaryaged students (and less iPad use) — as the focus shifts from learning-to-read to readingto-learn. However, this needs further inquiry. For the student participants, there were more boys than girls, and no further demographic information was collected beyond selfreported gender and age. Although the students discussed equity-related issues, the lack of data regarding socioeconomic status, race, or ethnicity also limits the generalizability of the findings. Other limitations include the nomination of focus group participants by the involved principal, and the potential for leading questions in the student survey. It is important to keep in mind the ever-changing rapid shifting of all technology implementation, including its school-based use, and to reflect upon research results in the timeline of technology implementation. In the case of this research, the study gathered data in the second year of the board's and the school's implementation of iPad technology. Much of the learning and adaptation was from a previous educator who came to the focus group but no longer worked at the school. Therefore, the changes in the technology, the support around it, and the availability of educational resources shifted significantly from the pilot year.

\section{Lessons Learned}

Many of the lessons learned in this instrumental case study are essential outcomes to consider for those planning and leading the implementation of iPads in school settings, such as funding agencies, school leaders (e.g., principals), board personnel, or technology managers.

1. Affect. Educators and students involved with iPad-infused classrooms in this case study believed in iPads as pedagogical tools - and enjoyed their use. It is possible 
(even likely) that use and attitude are closely linked when the iPad is seen as a mutually beneficial tool that supports growth and development in curricular areas. Therefore, it is important to consider attitude as well as pedagogy when implementing classroom sets of iPads-provide positive reinforcement for enthusiastic educators initiating iPad use in any small steps and "in planned and unplanned ways" (Courduff et al., 2016, p. 35).

2. Inclusivity. Planning for iPad implementation, when possible, should include a plan for implementation with more than a selected number of students, grades, and/or classrooms. Although finances will likely always be a factor for consideration, there are unique and creative ways of focusing on iPads for supporting universal design and differentiation, while not limiting their use to selected students or solely as an assistive technology tool.

3. Prerequisite skills. The acquisition of new technology is anticipated and celebrated in the modern system. However, often with the enthusiasm, administrators and teachers forget the learning required for the basic skills to use the device, as separate from using the tool as a learning device: "The critical component for consideration of usefulness and ease of use from a student perspective is largely ignored yet was found to be critical" (Courduff et al., 2016, p. 36). When both teachers and students have reached a comfort level in the basic pre-requisite skills of iPad use (e.g., keyboard, settings, swipes), initial frustrations can be bypassed so that the classroom can move on to "optimism, curiosity, risk taking, flexibility, and persistence" (Courduff et al., 2016, p. 37) in using the device as a teaching and learning tool.

4. Community supports. Educators enjoyed exploring the iPads on their own, but sought out community supports for their emotional, technical, and collaboration needs. As Beauchamp, Burden, and Abbinett (2015) have concluded: "Teachers learn to use, adopt and integrate technologies like the iPads in a highly experiential and playful fashion which carries with it significant implications of how we think about and reconfigure traditional professional development" (p. 172). It is essential to provide educators with readily available means to communicate, collaborate, and problem solve, so that the proximal and longer-term outcomes outweigh real and intangible start-up costs.

5. Ongoing technological supports. It is important to remember that educators will likely become both skilled and comfortable with iPad use with time and experience, moving past the "how and why" of first-order barriers (D'Agostino et al., 2016, p. 542). But it is equally important to know that any technological field-including tablet technology — changes as much (and as quickly) as procedural expertise grows. It is as imperative to proactively build in a plan for long-term, ongoing support (including funding) as it is to build a start-up community of support.

6. Effective school-based leadership. Effective school-based leadership is an essential area of support that is foundational to all others - and impossible when there is a dearth of it. Clearly, teaching using class sets of iPads is rewarding, yet is also a process including pedagogical risk, extensive changes to instructional methodology, and a series of adjustments over time and experience - an unfolding of processes and practices fine-tuned for the needs of each classroom. Effective school-based 
leadership is necessary to nurture this complex process from its inception as a possibility, to the concrete practicalities of making the use of classroom iPads a reality (e.g., funding), to ongoing support through both frustrations and celebrations, as educators move from exploring the functions of new technology to "its full potential for enhancing teaching and learning" (Blau \& Shamir-Inbal, 2016, p. 14).

In this research the obtainment of, and pedagogical pathways required for, the successful implementation of classroom-based iPads were clearly dependent on local initiatives, enthusiasm, and a shared local vision rather than on systems-wide universal funding or support ( $\mathrm{Li} \&$ Choi, 2014). Future research is required to examine the context of formal policy around iPad use as well as issues and/or practices with online safety (Male \& Burden, 2014), neither of which emerged as a concern in this study. The school we studied has built skilled personnel, empowered leaders, and a local community of engaged practice simply by having engaged in the pilot implementation; however, planned and supported access to a wider community of educational-technology-literate educators, along with concurrent and ongoing professional development, would better foster the essential conditions for success. A further element would be equitable accessin this case, access to long-term, adequate funding to expand the use of classroom sets of iPads and to provide ongoing, on-site technological supports for problem-solving and skills development: perhaps even emotional and behavioural support (Bruhn, Vogelgesang, Fernando, \& Lugo, 2016; Bruhn, Waller, \& Hasselbring, 2016). For example, administrative, technical, and/or professional support and expertise could be provided to delve deeply into the area of science instruction using iPads, in turn facilitated by jurisdictional policy. Nevertheless, like the educators in this study, the mutual benefits of engaged students enjoying learning appears to play an essential role in the effective, harmonious use of technology-infused teaching and learning, creating persistent educators (Wright, 2015) working for positive change and, above all, in student achievement.

\section{References}

ABCya.com LLC. (2010). Math bingo (Version 1.5) [Mobile application software]. Retrieved from http://itunes.apple.com

Animoto, Inc. (2013). Animoto video maker (Version 4.1.1) [Mobile application software]. Retrieved from http://itunes.apple.com

Anthony, A. B. (2012). Activity theory as a framework for investigating district-classroom system interactions and their influences on technology integration. Journal of Research on Technology in Education, 44(4), 335-356.

Apple, Inc. (2011). iCloud [Mobile application software]. Retrieved from http://itunes.apple.com

Apple, Inc. (2014). iPad in education results. Retrieved from https://www.apple.com/education /docs/iPad_in_Education_Results.pdf

Apple, Inc. (2015). Numbers [Mobile application software.] Retrieved from http://itunes.apple.com

Autodesk. (2013). 123d sculpt (Version 1.05) [Mobile application software]. Retrieved from http://itunes.apple.com

Beckman, K., Bennett, S., \& Lockyer, L. (2014). Understanding students' use and value of technology for learning. Learning, Media, and Technology, 39(3), 346-367. doi:10.1080/17439884.2013.878353 
Blau, I., \& Shamir-Inbal, T. (2016). Digital competences and long-term ICT integration in school culture: The perspective of elementary school leaders. Education and Information Technologies, 54(7), 1-19. doi: 10.1007/s10639-016-9487-8

Booyah, Inc. (2010). My Town 2 [Mobile application software]. Retrieved from http://itunes.apple.com

Bruhn, A. L., Vogelgesang, K., Fernando, J., \& Lugo, W. (2016). Using data to individualize a multicomponent, technology-based self-monitoring intervention. Journal of Special Education Technology, 31(2), 64-76. doi:10.1177/0162643416650024

Bruhn, A. L., Waller, L., \& Hasselbring, T. S. (2016). Tweets, texts, and tablets: The emergence of technology-based self-monitoring. Intervention in School and Clinic, 51(3), 157-162. doi: $10.1177 / 1053451215585803$

Carrot. (2011). Blackboard (Version 1.2) [Mobile application software]. Retrieved from http://itunes.apple.com

Chen, C. H. (2008). Why do teachers not practice what they believe regarding technology integration? The Journal of Educational Research, 102(1), 65-75.

Churchill, D., \& Wang, T. (2014). Teacher's use of iPads in higher education. Educational Media International, 51(3), 214-225.

Courduff, J., Szapkiw, A., \& Wendt, J. L. (2016). Grounded in what works: Exemplary practice in special education teachers' technology integration. Journal of Special Education Technology, 31(1), 26-38. doi:10.1177/0162643416633333

Crescenzi, L., Jewitt, C., \& Price, S. (2014). The role of touch in preschool children's learning using iPad versus paper interaction. Australian Journal of Language and Literacy, 37(2), 86-95.

Creswell, J. W. (2012). Educational research: Planning, conducting, and evaluating quantitative and qualitative research (4th ed.). Toronto, ON: Pearson.

Creswell, J. W. (2013). Qualitative inquiry and research design: Choosing among five approaches. Thousand Oaks, CA: Sage.

Cumming, T., \& Draper Rodriguez, C. (2013). Integrating the iPad into language arts instruction for students with disabilities: Engagement and perspectives. Journal of Special Education Technology, 28(4), 43-52.

D’Agostino, J. V., Rodgers, E., Harmey, S., \& Brownfield, K. (2016). Introducing an iPad app into literacy instruction for struggling readers: Teacher perceptions and student outcomes. Journal of Early Childhood Literacy, 16(4), 522-548. doi:10.1177/1468798415616853

Ditzler, C., Hong, E., \& Strudler, N. (2016). How tablets are utilized in the classroom. Journal of Research on Technology in Education, 48(3), 181-193. doi:10.1080/15391523.2016.1172444

Draper Rodríguez, C., Strnadová, I., \& Cumming, T. (2014). Using iPads with students with disabilities: Lessons learned from students, teachers, and parents. Intervention in School \& Clinic, 49(4), 244-250.

Dropbox. (2009). Dropbox (Version 3.9.3) [Mobile application software]. Retrieved from http://itunes.apple.com

Falloon, G. (2013). Young students using iPads: App design and content influences on their learning pathways. Computers \& Education, 68, 505-521. doi:10.1016/j.compedu.2013.06.006

Falloon, G. (2015). What's the difference? Learning collaboratively using iPads in conventional classrooms. Computers and Education, 84, 62-77. 
Flewitt, R., Kucirkova, N., \& Messer, D. (2014). Touching the virtual, touching the real: iPads and enabling literacy for students experiencing disability. Australian Journal of Language and Literacy, 37(2), 107-116.

Gillham, B. (2000). Case study research methods. London, UK: Continuum.

Glense, C. (1999). Becoming qualitative researchers. Upper Saddle River, NJ: Allyn \& Bacon.

Google, Inc. (2015). Google Maps [Mobile application software.] Retrieved from http://itunes.apple.com

Google, Inc. (2015). Google Search Engine [software.] Retrieved from https://google.ca

Hays, P. A. (2004). Case study research. In K. deMarrais \& S. D. Lapan (Eds.), Foundations for research: Methods of inquiry in education and the social sciences (pp. 217-234). Mahwah, NJ: Lawrence Erlbaum Associates.

Laferrière, T., Hamel, C., \& Searson, M. (2013). Barriers to successful implementation of technology integration in educational settings: A case study. Journal of Computer Assisted Learning, 29, 463-473. doi:10.1111/jcal.12034

Leer, R., \& Ivanov, S. (2013). Rethinking the future of learning: The possibilities and limitations of technology in education in the 21 st century. International Journal of Organizational Innovation, 5(4), 14-20.

Li, S. C., \& Choi, T. H. (2013). Does social capital matter? A quantitative approach to examining technology infusion in schools. Journal of Computer Assisted Learning, 30, 1-16. doi:10.1111/jcal.12010

Luterbach, K., \& Brown, C. (2011). Education for the 21st century. International Journal of Applied Educational Studies, 11(1), 14-32.

Male, T., \& Burden, K. (2014). Access denied? Twenty-first century technology in schools. Technology, Pedagogy, and Education, 23(4), 423-437.

McMillan, J. H. (2012). Educational research: Fundamentals for the consumer. Toronto, ON: Pearson.

Mertler, C. A., \& Charles, C.M. (2011). Introduction to educational research (7th ed.). Toronto, ON: Pearson.

Murray, O., \& Olcese, N. (2011). Teaching and learning with iPads, ready or not? Technology Trends, $55(6), 42-48$.

Nevosoft LLC. (2011). Pioneer lands (Version 1.3) [Mobile application software]. Retrieved from http://itunes.apple.com

Ontario Ministry of Education. (2006). The Ontario curriculum grades 1-8: Language (revised). Toronto, ON: Queen's Printer. Retrieved from http://www.edu.gov.on.ca/eng/curriculum /elementary/language18currb.pdf

Pellerin, M. (2013). E-inclusion in early French immersion classrooms: Using digital technologies to support inclusive practices that meet the needs of all learners. Canadian Journal of Education, 36(1), 44-70.

Pham, D. (2014). Mad math [Mobile application software]. Retrieved from http://itunes.apple.com

Quantum Victoria. (2013). Place value [Mobile application software]. Retrieved from http://itunes.apple.com

RIEU Limited. (2014). N+otes (Version 4.8.5) [Mobile application software]. Retrieved from http://itunes.apple.com

Rucarta. (2013). Space Mathematics: Addition and Subtraction (Version 1.1) [Mobile application software]. Retrieved from http://itunes.apple.com 
Schleicher, A. (2012). Preparing education systems for the 21st century. Education Review, 24(2), 6-12.

Shiny Things. (2014). Quick maths (Version 1.1.4) [Mobile application software]. Retrieved from http://itunes.apple.com

SocioCultural Research Consultants. (2013). Dedoose (Version 4.5) [Web application]. Retrieved from www.dedoose.com

Stake, R. E. (1995). The art of case study research. Thousand Oaks, CA: Sage.

Toronto Child \& Family Poverty Report Card Working Group. (2016). Divided city: Life in Canada's child poverty capital. Toronto, ON: Children's Aid Society of Toronto, Colour of Poverty Colour of Change, Family Service Toronto/Ontario Campaign 2000, and Social Planning Toronto. Retrieved from http://www.citynews.ca/wp-content/blogs.dir/sites/10/2016/11/14 /CAST-2016-report-v8-web.pdf

Turner, K. H. (2009). Flipping the switch: Code-switching from text speak to standard English. English Journal, 98(5), 60-65.

Ward, N., Finley, R., Keil, R., \& Clay, T. (2013). Benefits and limitations of iPads in the high school science classroom and a trophic cascade lesson plan. Journal of Geoscience Education, 61(4), $378-384$.

Webb, M. (2011). Changing models for researching pedagogy with information and communication technologies. Journal of Computer Assisted Learning (29)1, 53-67. doi:10.1111/j.13652729.2011.00465.x

Wendell, S. (1996). The rejected body: Feminist philosophical reflections on disability. New York, NY: Routledge.

Widjaja, D. (2011). Write 2 (Version 1.4) [Mobile application software]. Retrieved from http://itunes.apple.com

Wright, N. (2015). A case for adapting and applying continuance theory to education: Understanding the role of student feedback in motivating teachers to persist with including digital technologies in learning. Teachers and Teaching: Theory and Practice, 21(4), 459-471. doi:10.1080/13540602.2014.969105

Yin, R. K. (2003). Case study research: Design and methods (3rd ed.). Thousand Oaks, CA: Sage.

\section{Disclosure}

Carmen Hall is affiliated and collaborates with Apple, Inc., through its Apple Distinguished Educator program, which she joined in 2013. In 2015 Apple, Inc., provided funding unrelated to this research project to Kimberly Maich and Carmen Hall.

\section{Authors' Note}

Correspondence concerning this article should be addressed to Kimberly Maich, Memorial University, 230 Elizabeth Avenue, St. John's, NL, A1B 3X9, Canada. Email: kmaich@mun.ca 